\title{
Ignorancia deliberada: a propósito de la determinación del Dolo en el delito de Lavado de Activos
}

Eduardo Oré Sosa ${ }^{1}$

Abogado por la Pontificia Universidad Católica del Perú.

Doctor en Derecho por la Universidad de Salamanca. Magíster en Derecho con mención en Ciencias Penales por la

Universidad Nacional Mayor de San Marcos.

Profesor de Derecho Penal de la Universidad de Piura. Profesor de la Maestría en Derecho Penal de la Pontificia Universidad Católica del Perú.

Miembro del Instituto de Ciencia Procesal Penal-Incipp.

SUMARIO:

I. Introducción.

II. Definición de dolo.

III. Ignorancia deliberada.

1. Las siguientes líneas se corresponden con la ponencia presentada en el IV Congreso Internacional: Criminalidad Organizada Trasnacional. Homenaje al VIII Centenario de la Fundación de la Universidad de Salamanca — Lima, 3 al 5 de julio de 2018-, organizado por el Centro de Estudios de Derecho Penal Económico y de la EmpresaCEDPE y por el Observatorio de Criminalidad Organizada Trasnacional de la Universidad de Salamanca. Para esta publicación se ha visto por conveniente añadir, en notas a pie de página, algunos comentarios y las respectivas referencias bibliográficas. El artículo fue recibido con fecha 17-07-18. 


\section{RESUMEN:}

La presente contribución analiza el problema de la determinación del aspecto subjetivo del tipo, específicamente, del dolo. Más allá del debate entre las posturas cognitivas y volitivas del dolo, se aborda la cuestión de la denominada "ignorancia deliberada"; se trata de un criterio jurisprudencial de origen anglosajón que, a pesar de su cada vez más frecuente recepción por los tribunales, sobre todo en los procesos por tráfico ilícito de drogas, resulta de difícil encaje desde el punto de la dogmática penal.

Palabras clave: delito, imputación subjetiva, dolo, ignorancia deliberada, prueba.

\footnotetext{
ABSTRACT:

This article analyzes the problem of the determination of the subjective aspect of the crime type, specifically, intent. Beyond the debate between the cognitive and willful positions of intent, the question of the so-called "willful ignorance" is addressed; it is a jurisprudential criterion of Anglo-Saxon origin that, in spite of its increasingly frequent reception by the courts - specially in illegal drug traffic procedures, it is difficult to fit in from the point of view of criminal dogmatic.

Key Words: crime, subjective imputation, intent, willful ignorance, evidence.
}

\section{INTRODUCCIÓN}

Señores Organizadores del IV Congreso Internacional: Criminalidad Organizada Trasnacional. Señores miembros del Observatorio de Criminalidad Organizada Trasnacional de la Universidad de Salamanca. Estimados magistrados, docentes y colegas. Distinguida concurrencia:

Sean mis primeras palabras de gratitud a la gentil invitación para participar en este Congreso organizado en homenaje al octavo centenario de la fundación de la Universidad de Salamanca. Especialmente, quiero agradecer a mi amigo, Dr. Carlos Caro Coria, por brindarme el inmenso honor de intervenir en un evento que cuenta con la participación de nuestra querida maestra, la Catedrática Dra. Laura Zúñiga Rodríguez.

El día de hoy quiero compartir con ustedes, casi pensando en voz alta, algunas inquietudes sobre el aspecto subjetivo del delito de lavado de activos. Ciertamente, sería impensable hacer un completo análisis sobre este importante tema en los minutos asignados para esta ponencia, con lo cual, mi propósito no será otro que perfilar brevemente el problema de la determinación del dolo en el delito de lavado de activos.

Antes de ello, en tributo a los 800 años de la Universidad, quiero compartir con ustedes una de las tradiciones más conocidas que la ciudad de Salamanca ofrece a todos sus visitantes. Esta consiste en intentar hallar una rana que se encuentra incrustada en la fachada principal del Edificio Histórico de la Universidad de Salamanca. Algunas leyendas auguran éxitos en los estudios, buena suerte o pronto retorno a todos aquellos que encuentren la rana en aquel edificio de estilo plateresco, con lo cual, alguna dificultad ha de tener encontrar al mencionado batracio para que bien valga la pena hacerse a la tarea de ubicarlo en una fachada tan profusamente ornamentada.

Desde luego, podrán ustedes preguntarse por el motivo de esta quizás extravagante referencia que, aparentemente, poco tiene que ver con el delito de lavado de activos. No obstante, si se advierte que la rana, uno de los emblemas más conocidos de la ciudad, también llamada Helmántica, permanece casi oculta y es difícil de encontrar, evocaremos metafóricamente una de las características fundamentales del delito de lavado, a saber, el constituir una figura de ocultamiento, un delito en virtud del cual se pretende ocultar o disfrazar el origen delictivo y espurio de ciertos bienes.

Esto genera retos, por ejemplo, en el ámbito procesal. Si la prueba de cualquier delito no siempre es cosa sencilla, esto resulta mucho más difícil cuando hablamos del lavado de activos, pues los actos de conversión u ocultamien- 
to justamente tienen por finalidad disfrazar o ensombrecer el origen delictivo de los bienes, lo cual puede tener lugar a través de las más diversas formas: complejas tramas financieras, empleo de testaferros, constitución de empresas fachada en paraísos fiscales, negocios simulados, etc.

De esto, ya parece una verdad de Perogrullo señalar que el lavado de activos es un delito complejo, ipero hay que decirlo!, pues se trata de una figura que en cierta medida colisiona con el principio de legalidad, lo que ha llevado a Bajo Fernández a sostener que es difícil encontrar una figura delictiva que proporcione mayor inseguridad jurídica, que esté redactada de manera más lejana a la certeza jurídica, ni con redacción más imprecisa².

Estamos en verdad ante un delito que genera diversos problemas de interpretación, no es fácil arribar a consensos en temas como por ejemplo el bien jurídico protegido, punto en el cual ya resulta obligado citar a Muñoz Conde cuando señala que se trataría de un bien jurídico difuso, entre la Hacienda Pública y la Administración de justicia, que a pesar de su modernidad ha sufrido tantas modificaciones que, más que un cuerpo extraño del Derecho Penal, se ha convertido en un auténtico monstruo jurídico capaz de albergar en su interior todos los comportamientos que, por una $u$ otra causa, no son punibles sobre la base de otros tipos delictivos ${ }^{3}$.

Podrían agregarse otros temas como la sanción del autolavado, la autonomía del delito, la mezcla de activos de origen lícito con bienes de origen ilícito, y otros más, pero los citados son solo una muestra de los problemas que plantea el delito de lavado de activos a la doctrina y la jurisprudencia. No obstante, como adelanté al inicio de esta ponencia, en los minutos que restan me centraré en un tema no menos importante: la determinación del dolo en el delito de lavado de activos.

\section{DEFINICIÓN DE DOLO}

Si bien el dolo no viene definido expresamente en el Código penal, suele recurrirse al artículo 14 que excluye el dolo ante un error o desconocimiento de un elemento del tipo ${ }^{4}$; si el error es vencible, señala el legislador, se sancionará la conducta como culposa cuando se hallare prevista como tal en la ley. De esto, es fácil apreciar que la voluntad, concebida clásicamente como uno de los elementos del dolo, no juega formalmente ningún papel en la determinación del aspecto subjetivo del tipo ${ }^{5}$.

Sin embargo, hoy en día parte de la doctrina y la jurisprudencia todavía conciben el dolo como conocimiento y voluntad de realización de los elementos objetivos del tipo. Esta corriente, de-

2. BAJO FERNÁNDEZ, Miguel. "El desatinado delito de blanqueo de capitales". En AA. VV. Política criminal y blanqueo de capitales. Miguel Bajo y Silvina Bacigalupo —editores-. Madrid: Marcial Pons, 2009, p. 7.

3. MUÑOZ CONDE, Francisco. "El delito de blanqueo de capitales y el Derecho Penal del enemigo". En: III Congreso sobre prevención y represión del blanqueo de dinero. Abel Souto y Sánchez Stewart —coordinadores-. Valencia: Tirant lo Blanch, 2013, p. 375.

4. En el mismo sentido, con respecto al ordenamiento español, vid. FEIJOO SÁNCHEZ, Bernardo. "La teoría de la ignorancia deliberada en Derecho Penal: una peligrosa doctrina jurisprudencial". En: Revista Indret, № 3. Barcelona: 2015, p. 17.

5. Al respecto, García Cavero sostiene que en un Derecho Penal que se encarga de proteger bienes jurídicos frente a ataques dirigidos a lesionarlos, resulta lógico entender que la acción más grave desde el punto de vista subjetivo es aquella que contiene una voluntad específica de lesionar el bien jurídico, con lo cual, ahí el dolo requerirá de un elemento volitivo referido al resultado lesivo; sin embargo, en un Derecho Penal que se encarga de evitar la creación de riesgos prohibidos, resulta lógico que el elemento volitivo deje de ser decisivo y el centro del reproche se encuentre en el conocimiento de la generación de los riesgos prohibidos, vid. GARCÍA CAVERO, Percy. Derecho Penal. Parte General. Segunda edición. Lima: Jurista Editores, 2012, p. 490. 
nominada teoría volitiva del dolo, suele reconocer distintas formas de dolo: dolo directo, dolo de consecuencias necesarias y dolo eventual.

No obstante, como señala Ramón Ragués, una aplicación coherente del dolo definido como voluntad llevaría a castigar como meras imprudencias supuestos que ante los ojos de cualquier espectador parecen mucho más cercanos al merecimiento de pena propio de los comportamientos dolosos ${ }^{6}$.

Si no pensemos en el caso de José María Bultó, un empresario español secuestrado por un grupo terrorista catalán y al que se le colocó un artefacto explosivo en el tórax, artefacto que solo sería retirado si el empresario entregaba la suma de 500 millones de pesetas. Los terroristas instruyeron a la víctima con las precauciones necesarias para que el artefacto no explote hasta su segura desactivación; no obstante, el artefacto explotó ocasionándole la muerte. Por increíble que parezca, los abogados de los terroristas adujeron falta de dolo y que, en todo caso, el homicidio calificaría ¡como culposo! Cierto es que quien está a punto de ahogarse se aferra hasta a la más pequeña astilla, pero como señala Sánchez-Vera, tal argumento encontraba fundamento fáctico y jurídico al menos en ese momento de evolución dogmática de la teoría del dolo, pues, efectivamente, podía argumentarse que los terroristas no querían ni tenían la voluntad de matar al empresario, pues lo querían vivo para cobrar el rescate y porque le dieron precisas instrucciones para que la bomba no explote?.

Las severas críticas dirigidas contra el elemento volitivo originaron un continuo replanteamien- to del contenido de la voluntad; los partidarios de las corrientes volitivas terminaron ampliando el concepto de voluntad para comprender en él no solo a la intención, sino también a la aceptación o resignación frente al resultado. Sin embargo, como señala Ragués, aceptar, conformarse o resignarse son requisitos pseudovolitivos que se deducen de la circunstancia de que un sujeto no haya desistido de su conducta pese a ser consciente del riesgo típico que ella conllevaba ${ }^{8}$.

Todo esto ha terminado por otorgar en la práctica de nuestros tribunales, por más que se siga definiendo el dolo como conocimiento y voluntad, un exclusivo protagonismo al elemento cognitivo, es decir, al conocimiento, a la representación del agente de realizar una conducta ex ante peligrosa: actúa con dolo no quien tiene la voluntad, sino quien es consciente de realizar un comportamiento que crea un riesgo prohibido de aquellos que quieren ser evitados por el tipo penal.

Esto supone claramente un concepto normativo; de ahí que podamos afirmar con Hruschka que en la afirmación de que alguien ha actuado dolosamente, el dolo, como todo lo espiritual, no se constata ni se prueba, sino que se imputa?

Por señalar algunos ejemplos, se puede determinar que aquel que dispara a la cabeza de otro, le coloca un potente veneno en una taza de té o le clava sesenta puñaladas certeras en el pecho, lo hace con conocimiento pleno de lo que realiza, a saber, una conducta que por generar un elevado riesgo de acabar con la vida de una persona tiene precisamente el sentido social de matar; esto con

6. RAGUÉS I VALLES, Ramón. “Consideraciones sobre la prueba del dolo". En: Revista de Estudios de la Justicia, N 4. Santiago de Chile-Universidad de Chile: 2004, p. 13.

7. SÁNCHEZ-VERA GÓMEZ TRELLES, Javier. "Nuevas tendencias normativistas en el concepto y la prueba del dolo". En: Revista Derecho Penal y Criminología, N 79. Bogotá-Universidad Externado de Colombia: 2005, pp. 100-101.

8. RAGUÉS I VALLES, Ramón. Op. Cit., pp. 14-15.

9. HRUSCHKA, Joachim. "Sobre la difícil prueba del dolo". En: Imputación y Derecho Penal. Estudios sobre la teoría de la imputación. Segunda edición. Buenos Aires: B de F, 2009, p 195. 
independencia de lo que haya pasado efectivamente por la mente del autor, algo inaccesible al juez. Con lo cual, quien realice tales conductas solo puede responder a título doloso.

Por esta razón, diversos autores, entre ellos Javier Sánchez-Vera, consideran que para la determinación del dolo, la constatación de la voluntad es fútil, superflua y, por ende, renunciable; la relación entre el elemento cognitivo y el volitivo es ineludible: siempre que se conoce el riesgo creado y a pesar de ello se actúa, se quiere su realización, al menos en un sentido normativo ${ }^{10}$.

De esta suerte, se excluye una noción psicologicista de dolo entendido como un estado mental ${ }^{11}$ que exigiría del Juez hurgar en el fuero interno del autor para tratar de determinar qué pasó por su mente o cuáles fueron sus más recónditos pensamientos.

\section{IGNORANCIA DELIBERADA}

Ahora bien, como se recuerda, los tipos penales previstos en el Decreto Legislativo 1106 sobre el lavado de activos exigen una determinada característica del objeto material de este delito, a saber, que provengan de una actividad criminal. En efecto, en lo que ahora concierne, el legislador señala que, con respecto al dinero, bienes, efectos o ganancias, el agente debía conocer o "debía presumir" el origen ilícito de dichos activos. Surge así la duda sobre si la referencia a que debía presumir supone la recepción en nuestro ordenamiento de aquellos supuestos conocidos como "ignorancia deliberada", es decir, aquellos en los cuales pese a que el agente desconoce que realiza un injusto se termina haciéndolo responsable a título doloso.

Como se advierte, se quiere incorporar una forma de dolo donde ya no solo resulta prescindible la voluntad, sino también el conocimiento.

Y este parece ser el talón de Aquiles de dicha propuesta, pues si como señalamos anteriormente hoy en día el dolo se reduce en la práctica judicial al conocimiento de los elementos del tipo objetivo, mal se hace ahora en prescindir también de este elemento cognitivo. Con ello, el dolo resultaría vaciado de contenido.

Estas críticas se dirigen, ciertamente, contra la forma más pura o estricta de ignorancia deliberada ${ }^{12}$, es decir, aquellos casos en los que no cabe imputar cabalmente el conocimiento de haber creado un riesgo prohibido. No estamos hablando de aquellos casos en los que el imputado alega simplemente desconocer.

Pues seamos honestos, ¿cuántas veces han visto ustedes que el autor de un delito se haya presentado a la autoridad para declararse culpable y que le pongan las esposas?, ¡claro que dirá que no hizo nada! o, en el mejor de los casos, que no sabía lo que hacía, pero que el imputado invoque desconocimiento, no quiere decir que desconozca; con lo cual, sus meras declaraciones no impiden necesariamente una imputación a título doloso.

10. SÁNCHEZ-VERA GÓMEZ TRELLES, Javier. Op. Cit., p. 102.

11. MIRÓ LLINARES, Fernando. “¿Dime qué sabes y te diré de qué respondes? El dolo del cooperador necesario en el moderno Derecho penal". En: Diario La Ley, N 8077. Madrid: 2013, p. 4. Según este autor, la consideración psicologicista del dolo como un estado mental conllevaba la tesis de que el mismo debía ser probado; mientras que la consideración del dolo como un elemento perteneciente a lo jurídico — normativo— nos obliga a recordar que el dolo no puede describirse, sino imputarse: "Lo que los tribunales realizan por medio de la prueba indiciaria no es, por tanto, "descubrir lo subjetivo a partir de lo objetivo», sino más bien atribuir un sentido normativo, relativo al conocimiento que socialmente se va a atribuir a las personas, a partir de los hechos que parecen haberse producido en la realidad".

12. Esto en contraposición a aquellos casos en los cuales el agente tiene ante sí elementos que le pueden hacer sospechar de la presencia de un injusto, pero prefiere no indagar, mantenerse en el "desconocimiento". Como se verá posteriormente, estos casos son asimilables al dolo eventual. 
Pero como dice el refrán: algo tendrá el agua cuando la bendicen. ¿A qué se deberá la relativa fama de esta sugerente postura doctrinal y jurisprudencial de origen anglosajón? Para responder esto, viene a cuento un ejemplo reseñado por Ramón Ragués ${ }^{13}$ al abordar el tema de la ignorancia deliberada: "se trata de un testaferro profesional que, a cambio de una retribución, acepta figurar como administrador formal de cientos de sociedades de las que no le importa lo más mínimo la actividad real o quiénes son sus verdaderos gestores", y así se pregunta el Catedrático de la Universidad Pompeu Fabra: "Cómo debe enfrentarse a los casos de ignorancia deliberada un Derecho Penal que considera el conocimiento como un elemento básico de la responsabilidad? ¿Resulta aceptable que un sujeto que ha buscado permanecer en el desconocimiento se beneficie penalmente de tal circunstancia?".

El mismo Ragués concluye que en aquellos casos en los que el sujeto ha contado con una sospecha inicial de que su conducta podía resultar lesiva para algún interés penalmente relevante, pero ha preferido mantenerse en un estado de ignorancia como una estrategia para, llegado el caso, poder alegar dicha ignorancia en su descargo, se advierte una necesidad de sanción similar a la de los casos de dolo eventual y, desde luego, superior a los supuestos habituales de negligencia ${ }^{14}$.

Pero bien visto, no es que estemos ante un caso que merezca una sanción similar al dolo eventual, jes que se trata justamente de un caso de dolo eventual! Con Feijoo Sánchez, se puede decir que en la mayoría de los supuestos en los que se aprecia ignorancia deliberada no plantearía problemas la calificación como dolo eventual; y con respecto al ejemplo planteado por Ragués -el caso del testaferro profesional que, a cambio de una retribución, acepta figurar como administrador formal de cientos de sociedades-, el testaferro es consciente de que está participando en una simulación; y el que es consciente de que se incorpora a una simulación organizada por terceros no necesita saber más para responder por dolo eventual ${ }^{15}$.

De esta manera, quien es consciente de su cooperación en un hecho ilícito responde de las posibilidades razonables que se desprendan de su participación; no responde, desde luego, de las posibilidades que se entiendan como imprevisibles. Así, quien por encargo de un desconocido y a cambio de 5,000 dólares acepta llevar dentro de su equipaje un extraño paquete de Lima a Ámsterdam, puede representarse, como señala Miró Llinares ${ }^{16}$, que está participando en un injusto; esta máxima de la experiencia hace que pueda responder por un delito de tráfico ilícito de drogas. La defensa podrá argumentar que como no le constaba el contenido del paquete no hubo conocimiento, y por tanto no cabe calificar la conducta como dolosa, pero ¿tenía realmente que constarle eso? ¿Y si fuese así, en qué área del cerebro del autor vamos a hallar dicha información? ¿Cuesta tanto desprenderse de este concepto psicologicista de dolo?

Una vez más, debe afirmarse que el dolo se atribuye, lo que se debe imputar al agente es la representación del riesgo típico creado con su conducta. Como señala Miró Llinares:

"la consideración del dolo como un elemento normativo, nos obliga a recordar que el dolo no puede describirse, sino imputarse a

13. RAGUÉS I VALLES, Ramón. "Mejor no saber. Sobre la doctrina de la ignorancia deliberada en Derecho Penal". En: Revista Discusiones N XIII-2. Buenos Aires-Universidad Nacional del Sur: 2013, pp. 11-12.

14. Ibíd., p. 33.

15. FEIJOO SÁNCHEZ, Bernardo. Op. cit., pp. 19-20.

16. MIRÓ LLINARES, Fernando. "Dolo y derecho penal empresarial: debates eternos, problemas modernos". En: Revista Cuadernos de Política Criminal, № 113. Madrid: 2014, pp. 224-225. 
alguien a partir del conjunto de las circunstancias externas que aportan para la determinación de aquello que socialmente es considerado como un actuar doloso"m7.

Y para esta tarea debemos apelar a las reglas de la experiencia que ostenten un amplio consenso social, como señala Ramón Ragués ${ }^{18}$. Y es justamente esa regla o máxima la que nos permite valorar que cualquier ciudadano que transporta un paquete de Lima a Ámsterdam, por encargo de un desconocido, a cambio de una considerable cantidad de dinero puede representarse el peligro de verse involucrado en una actividad delictiva.

Desde luego, lo que no se le podrá atribuir es la representación de riesgos inesperados, como que el paquete contenía una bomba, pues en dicho caso la máxima de la experiencia apuntaría más bien en otro sentido: nadie que estime su vida correría semejante riesgo.

Ahora bien, cierto es que se ha querido encontrar algún fundamento para los casos de ignorancia deliberada en estricto, recurriéndose así a los deberes de incumbencia consustanciales a los delitos de infracción de deber. Con respecto a este punto, Sánchez-Vera señala que el sujeto que dice desconocer los riesgos creados por su actuación y como todo motivo para ello alega desidia, simple "ceguera ante los hechos", obra con dolo cuando se pueda constatar que le incumbía un deber especial de conocimiento ${ }^{19}$.

No obstante, como bien señala Feijoo Sánchez, esto nos puede conducir a tratar como dolosos casos de error de tipo, lo que se opone frontal- mente a la regulación rígida que hace el legislador sobre esta materia en el artículo 14 del Código Penal. Como se recuerda, este precepto deja claro que todo error $y$, por tanto, desconocimiento, de la situación típica excluye el dolo. $Y$, como el mismo Feijoo refiere, no se trata de convertir en dolo lo que no lo es ${ }^{20}$.

En este orden de ideas, si en atención a las reglas de la lógica, la ciencia y las máximas de la experiencia un Juez puede atribuir al agente la representación suficiente de aquellos elementos que configuran el injusto típico, la responsabilidad será dolosa; esto es así, incluso en aquellos casos en que dicha representación no sea segura, pues para el dolo no es necesario un conocimiento fuera de toda duda ${ }^{21}$, como sucede con el dolo eventual.

Sin embargo, ante un déficit de conocimiento, es decir cuando el Juez no pueda atribuir al procesado la representación de los elementos básicos que configuran el injusto típico, excluirá la responsabilidad dolosa; con lo cual, para aquellas situaciones de ignorancia deliberada en estricto será preferible, como apunta Miró Llinares, la regulación expresa de tipos concretos que atiendan a posiciones específicas de deber en los cuales se le puede exigir al sujeto responsable que no se sustraiga arbitrariamente al conocimiento de los efectos de sus acciones en su propio beneficio ${ }^{22}$.

Ahora bien, podemos preguntarnos cómo se ha de imputar el dolo para una condena por lavado de activos. Al respecto, del fundamento número 21 de la Sentencia Plenaria Casatoria 1-2017 de la Corte Suprema se desprende que resulta necesa-

17. MIRÓ LLINARES, Fernando. Op. Cit., p. 4.

18. RAGUÉS I VALLES, Ramón. Op. Cit., p. 20.

19. SÁNCHEZ-VERA GÓMEZ TRELLES, Javier. Op. Cit., p. 107.

20. EIJOO SÁNCHEZ, Bernardo. Op. Cit., pp. 17-22.

21. Ibíd., p. 17-18.

22. MIRÓ LLINARES, Fernando. Op. Cit., p. 235. 
ria la convicción más allá de toda duda razonable, de los elementos que configuran el delito, y en lo que al aspecto subjetivo concierne, tanto el conocimiento de la procedencia ilícita de los activos, como de realizar las conductas propias de lavado, es decir, las de convertir, transferir, ocultar, poseer, transportar, etc. A ello se ha de agregar, dada la configuración típica de este delito, un elemento de tendencia interna trascendente, a saber, la finalidad de evitar la identificación, incautación o decomiso de los bienes objeto material del delito.

La determinación de la concurrencia de los elementos del tipo habrá de hacerse mediante la prueba por indicios, como se ha puesto de manifiesto innumerables veces por la doctrina y la jurisprudencia ${ }^{23}$. No me extenderé en este punto, pues la siguiente mesa abordará los aspectos procesales de este delito.

En todo caso, ya concluyendo para felicidad de todos ustedes, solo traigo a colación algunos criterios que fueron recogidos en el fundamento número 34 del Acuerdo Plenario 3-2010 sobre el delito de lavado de activos. Se trata de datos o indicios que debidamente incorporados y acreditados durante el proceso, y en la medida que sean sólidos, concordantes y convergentes serán de gran utilidad para valorar la concurrencia de los elementos típicos de este delito. Estos criterios, resumidamente, son los siguientes:

a) Los incrementos patrimoniales injustificados;

b) El manejo de grandes sumas de dinero en efectivo;

c) Las operaciones sobre activos en las que, por valerse de testaferros, sociedades instrumentales, o depósitos o apertura de cuentas en paraísos fiscales, pongan de manifiesto operaciones extrañas a las prácticas comerciales ordinarias;

d) La inexistencia de negocios lícitos que justifiquen el incremento patrimonial o las transmisiones dinerarias;

e) La debilidad de las explicaciones acerca del origen lícito de los activos; o sobre lo anómalo de las operaciones detectadas;

f) La constatación de algún vínculo o conexión con actividades delictivas previas o con personas o grupos relacionados con las mismas.

Fíjense en esto último, es decir, en el riesgo que puede suponer ahora la vinculación que se pueda establecer con personas relacionadas con actividades delictivas, pues no estamos en los tiempos evocados en la Letra Escarlata, donde un culpable quedaba marcado en lugar visible con el símbolo de su delito. ¿Cómo saber así con quién nos relacionamos?

Desde luego, más preocupados habrán de estar aquellos con cierta debilidad por las actividades criminales, pues en el mundo frenético de hoy donde todo es fugaz y nada dura para siempre, los socios, cómplices y amigos de antaño, pueden convertirse en los más acérrimos enemigos. Por esta razón, quizás ellos enfrenten un dilema que puede expresarse con las palabras del gran Jacinto Benavente en una de sus más afamadas obras, a saber, que para salir adelante en todo, mejor que crear afectos es crear intereses.

Esto es lo que quería compartir con ustedes, y solo me resta agradecer la infinita paciencia que han tenido conmigo el día de hoy.

Muchas gracias.

23. Sostienen que la prueba indirecta o por indicios es la más usual, entre otros, GARCÍA CAVERO, Percy. Op. Cit., p. 115; PARIONA PASTRANA, Josué. El delito precedente en el delito de Lavado de activos. Aspectos sustantivos y consecuencias procesales. Lima: Instituto Pacífico, 2017, pp. 144-146; PÁUCAR CHAPPA, Marcial. La investigación del delito de lavado de activos. Tipologías y jurisprudencia. Lima: Ara Editores, 2013, pp. 183 y ss.; GÁLVEZ VILLEGAS, Tomás. El delito de lavado de activos. Criterios sustantivos y procesales. Análisis del Decreto Legislativo $N^{\circ} 1106$. Lima: Actualidad Penal, 2014, pp. 676 y ss. Por lo demás, el artículo 10 del Decreto Legislativo 1106 prescribe: "El origen ilícito que conoce o debía presumir el agente del delito podrá inferirse de los indicios concurrentes e cada caso". 